\title{
CFD Evaluation of Directional Variation Effects of the Air Supply Diffuser for the International Space Station Cabin Atmosphere
}

\author{
Nikolay Ivanov ${ }^{1, *}$, Evgueni Smirnov ${ }^{1}$, Chang H. Son ${ }^{2}$, and Denis Telnov ${ }^{3}$ \\ ${ }^{1}$ Peter the Great St. Petersburg Polytechnic University, St. Petersburg, 195251 Russia \\ ${ }^{2}$ The Boeing Company, Houston, TX, 77059, USA \\ ${ }^{3}$ New Technologies and Services, St. Petersburg, 197198 Russia
}

\begin{abstract}
The International Space Station (ISS) crew health and safety depend on ventilation system performance. The ISS ventilation system comprises of numerous air supply diffusers. For each ISS module design of the ventilation system and, in particular, supply diffuser distribution and configuration, is based on the assumption that the cabin aisle way is clear of any objects. However, on-orbit operations could lead to short- or long-term blockage of the area near the air supply diffuser due to some items or stowed bags necessary for the station operation. Partial blockage of the diffuser could disrupt the free jet airflow or change its intended direction. The current contribution is devoted to examination of the ISS research module - the U.S. Laboratory - ventilation system performance in case of partial inlet diffuser blockage with objects, such as Cargo Transfer Bag. The goal of the study is to assess the localized effects when the blockage occurs in the module interior for a possible stagnant zones formation. The paper presents detailed analysis of the diffuser blockage effects on airflow characteristics in various zones in the ISS habitat.
\end{abstract}

\section{Introduction}

Maintaining of a safe living and workspace on board the International Space Station (ISS) by keeping a wellventilated environment is very important. As forced convection is the only mechanism for air mixing under microgravity conditions, an effective ventilation system is required to provide comfortable thermal conditions and good air quality in habitable volume. For the ISS ventilation system design, an assumption that cabin aisle way is clear from the objects for airflow is used. However, during the ISS operation various items stowed within its habitable volume may lead to partial blockage of the aisle way. When the stowage object is located near a ventilation diffuser, this partial blockage of the diffuser could lead to disruption of global airflow pattern and affect the ISS module cabin atmosphere. Hence, it is necessary to control that air supply diffusers have sufficient clearance for proper ventilation. To avoid any negative impact on the functionality of Environmental Control and Life Support Systems (ECLSS), avoid stowing items in certain locations is recommended [1]. These areas are located around smoke detectors, emergency equipment and air intakes and diffusers. Keep Out Zones (KOZ) are determined for each intake and diffuser for this purpose. However, short- or longterm cluttering of the space near a ventilation diffuser with some items are unavoidable for daily ISS operation.

Effect of obstacles in the path of a jet supplied from a ventilation diffuser has been under study previously; most attention was paid to the wall-attached obstacles influence on wall jets. Awbi and Setrak [2] investigated experimentally and numerically the effect of surfacemounted single and multiple obstacles in the way of a 2D wall jet. Velocity data presented showed noticeable acceleration of jet decay, as well as strong influence of the obstacle height and position on the jet separation from the surface. Nielsen [3] also concluded that the maximum velocity in the wall jet as well as the maximum velocity in the occupied zone could be reduced considerably due to ceiling-mounted obstacles.

Obstacle effects on the airflow behavior were studied experimentally in [4] for a particular case of uniform flow push-pull ventilation system. Smoke visualization demonstrated visible disturbances of the flow pattern due to the obstacle (manikin) placement in the ventilated zone; the particular features of the flow pattern depend strongly on the obstacle position; however, as there is no accentuated jet at the inlet, the flow pattern returns to its original shape downstream the obstacle.

In case of free jets spreading from the diffusers, the presence of obstacles inside a ventilated room can disrupt the free jet airflow or change its supposed direction. Analysis of convective heat transfer in the orbiter middeck for the Shuttle rescue mission [5] showed that ventilation characteristics and convective heat transfer within the Shuttle Orbiter middeck cabin in the presence of seven suited crewmember manikins and seven Individual Cooling Units (ICU) are strongly affected by the air jet interaction with an obstacle (neighboring crewmember). Air jets issued from the ICU exhausts meet an obstacle and cannot penetrate into the

\footnotetext{
* Corresponding author: ivanov_ng@spbstu.ru
} 
cabin, as a result short-circuiting of hot air occurs that leads to poor heat transfer conditions.

Effect of pronounced partial blockage of the ISS module interior was studied in [6]: the paper considered the maximum stowage configuration of the Node 1 ISS module called "Unity" when a number of Cargo Transfer Bags (CTBs) temporarily occupies the module aisle way. The CTBs are fabric cargo containers, which conform to specific dimensional and material requirements for space flight, and are currently used to transfer cargo to and from the ISS [7]. As the module linear diffusers were not blocked in the case considered, the flow field did not contain pronounced stagnant zones and satisfied the velocity requirements.

Parametric CFD analysis performed for the U.S. Laboratory "Destiny" ISS research module with the box of small size placed within the $\mathrm{KOZ}$ volume at various locations is presented in [8]. It was shown that the small $3 \times 3$ inches size box placement within the $\mathrm{KOZ}$ at the distance up to 6 inches from the diffuser face does not affect the ISS module cabin atmosphere. A comparison of the airflow patterns in the U.S. Laboratory cabin aisle way resulted in conclusion that partial blockage of the diffuser does not disturb the main air jets issued from the diffuser. The airflow patterns are slightly sensitive to the box position, but neither for centered nor for sidewaysshifted box there was no weakening of the inlet air jets.

The goal of the present study, performed with the ANSYS Fluent 18 Computational Fluid Dynamics (CFD) software, is to assess the effect of a supply diffuser cluttering on the airflow within the U.S. Laboratory with large boxes, single of coupled CTB. Dimensions of the CTB are $19.75 \times 16.75 \times 9.75$ inches that corresponds to $50.17 \times 42.5 \times 24.76 \mathrm{~cm}$, so that the volume of each CTB is about $0.05 \mathrm{~m}^{3}$ [7]. The U.S. Laboratory module is the primary research laboratory of the ISS. As a pressurized module with volume of about $106 \mathrm{~m}^{3}$ (3700 cubic feet), it comprises three sections and two endcones and serves as a work space for astronaut's research. The paper presents results of four CFD runs performed for various scenarios of CTB location in comparison with the data without any cluttering. Localized effects of blocking the module interior on formation of stagnant zones with poor airflow are examined and discussed.

\section{Computational Model}

\subsection{Cabin Aisle Way Geometry Model and Airflow Boundary Conditions}

Figure 1 illustrates geometry models adopted for the CFD analysis of the U.S. Laboratory module ventilation. The computational domain includes one module only, operation of the inter-module ventilation (IMV) base on connections with other ISS modules is modeled by means of boundary conditions at the corresponding inlet/outlet openings. The geometry model does not include any internal equipment in the module aisle way, except the CTBs placed near diffusers.
Four configurations were considered in the current study. Case 1 is the reference case with free cabin aisle way (no CTBs, i.e. no diffuser blockage). In Case 2 two port side diffusers and two starboard side diffusers are blocked with single CTBs (Figure 1a). In Case 3 the same four diffusers are blocked with paired CTBs (Figure 1b). In Case 4 one port side diffuser and one starboard side diffuser are blocked with paired CTBs (Figure 1c).

The active supply diffusers (intake openings; being inlets for the flow domain analyzed) and return grilles (exhaust openings; being outlets for the flow domain analyzed) as well as open hatches are marked in Figure 1. The airflow boundary conditions adopted for the U.S. Laboratory are summarized in Table 1.

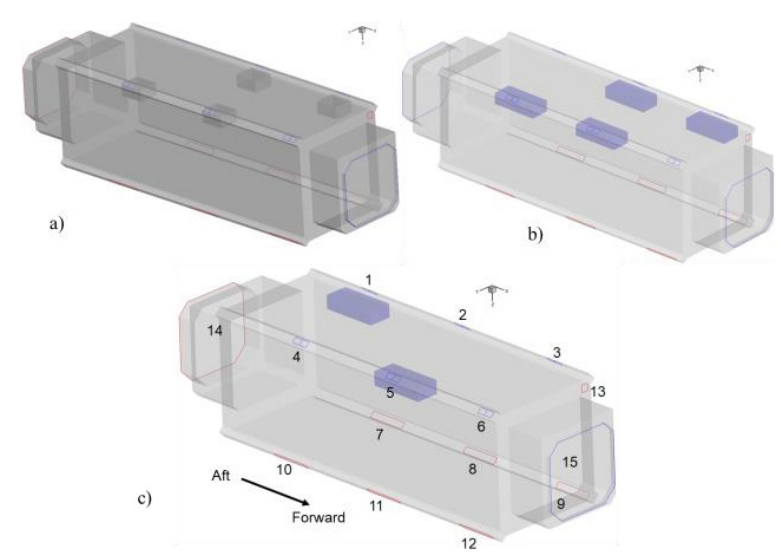

Fig. 1. Geometry model used for the CFD study of the U.S. Laboratory: (a) Case 2 with four single CTBs, (b) Case 3 with four paired CTBs, (c) Case 4 with two paired CTBs, numbers mark the active openings.

Table 1. List of Airflow Boundary Conditions.

\begin{tabular}{|c|c|c|c|}
\hline $\begin{array}{c}\text { Boundary } \\
\text { № }\end{array}$ & Name & Type & $\begin{array}{c}\text { Flow } \\
\text { Rate, } \\
\text { cfm }\end{array}$ \\
\hline $1,2,3$ & Port CD & inlet & 50 \\
\hline $4,5,6$ & Starboard CD & inlet & 50 \\
\hline $7,8,9$ & Port RG & outlet & -45 \\
\hline $10,11,12$ & Starboard RG & outlet & -45 \\
\hline 13 & Forward-Port IMV & outlet & -120 \\
\hline 14 & Aft Hatch & outlet & -30 \\
\hline 15 & Forward Hatch & outlet & 120 \\
\hline
\end{tabular}

The complete U.S. Laboratory ventilation scheme is described in details in [9]. 4. Six common diffusers (CD, openings from №1 to №6 in Figure 1) are placed in the 
ceiling corner pockets of the racks and supply cabin with air at a given flow rate of $50 \mathrm{cfm}$ each (300 cfm total). The velocity inlet boundary condition is set for each half of each open diffuser with the velocity specification method of velocity magnitude and flow direction components. The flow angles in the aft-forward direction with respect to the normal are $30^{\circ}$ and $-30^{\circ}$ for each half of the CD. The starboard CDs direct the flow across the ceiling towards the port direction (the deviation from the normal to the diffuser surface is $25^{\circ}$ ), while the port CDs direct the flow across the port side wall towards the floor (also with the $25^{\circ}$ deviation from the normal to the diffuser surface).

Six return grilles (RG, openings from №7 to №12 in Figure 1) are placed in the floor corner pockets of the racks. The total flow rate leaving the U.S. Laboratory cabin through the return grilles is $270 \mathrm{cfm}$. According to the IMV scenario, $90 \mathrm{cfm}$ of air from return grilles are moved to Node 1 via an IMV duct. Remaining $180 \mathrm{cfm}$ from return grilles and $120 \mathrm{cfm}$ of IMV air (from Node 3 , i.e. initially clean air from the Russian On-Orbit Segment, ROS) are supplied to the common diffusers. The remaining $120 \mathrm{cfm}$ of cabin air are collected in the forward-port IMV return grille (№13 in Figure 1), and then supplied to Node 2 via a duct.

The forward U.S. Laboratory hatch connecting the module with Node 2 (marked as №15 in Figure 1) is open. According to the IMV scheme, $120 \mathrm{cfm}$ of Node 2 cabin air come to the U.S. Laboratory through the hatch; in the current study the hatch is treated as the inlet boundary. The aft hatch connects the U.S. Laboratory cabin with Node 1 (№14 in Figure 1), and it is open also; $30 \mathrm{cfm}$ of cabin air leaves the module through this hatch.

The uniform velocity approximation is assumed as the inlet at each common diffuser and at the hatch №15. The uniform velocity distributions with the corresponding negative velocity values are set at the return grilles and IMV outlets. The no-slip boundary condition is imposed on all the solid surfaces. The air is assumed to be an incompressible fluid. The properties of the fluid are as follows: density of $\rho=1.225 \mathrm{~kg} / \mathrm{m}^{3}$, and dynamic viscosity of $\mu=1.8 \times 10^{-5} \mathrm{~kg} / \mathrm{m}$-s.

\subsection{Computational Aspects and Turbulence Modeling}

The computational grid used in the ventilation CFD modeling is fully unstructured with polyhedral mesh elements. The initial grid was created from tetrahedral mesh elements using the GAMBIT 2.4.6 generator. The grid is clustered to the solid walls and to the diffusers. Figure 2 illustrates the tetrahedral computational mesh at a section crossing common diffuser №5 for the cases with and without neighboring CTB.

The computations have been performed with the parallel version of the ANSYS Fluent 18 CFD software. The Fluent solver, being face-based, supports polyhedral cells. The advantages that polyhedral meshes have shown over some of the tetrahedral or hybrid meshes is the lower overall cell count, almost 3-5 times lower for unstructured meshes than the original cell count, keeping the same spatial accuracy. Conversion of the initial tetrahedral grid to polyhedral one was performed in Fluent. The clustering of the grid to the walls and to the diffusers was kept during the conversion procedure. The final polyhedral grids consisted of about two million cells (that corresponds to about ten million nodes).

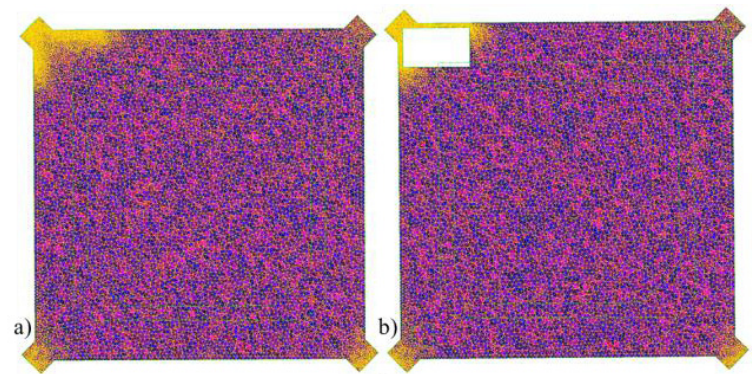

Fig. 2. Computational mesh at a section crossing common diffuser №5: (a) Case 1 without CTBs, (b) Case 2 with single CTBs.

The Reynolds-Averaged Navier-Stokes (RANS) approach was used. The RANS-based modeling approach greatly reduces the required computational effort and resources, and it is widely adopted for practical engineering applications. For the ISS ventilation case, a comparison of the Columbus experimental data with the results of 3D RANS computations as well as with the accurate Large Eddy Simulation computations prove that RANS modeling is quite accurate regarding the air ventilation velocity field $[10,11]$.

The realizable k- $\varepsilon$ model [12] with the standard wall functions [13] was used for computations. The wall distance of a cell center adjacent to a solid wall measured in wall units, $\mathrm{y}_{\mathrm{p}}{ }^{+}$, ranged from 10 to 50 over the majority of the solid walls. The inlet turbulence intensity was taken as $10 \%$ for all the diffusers while the inlet ratio of the turbulent to molecular viscosity, $v_{\text {tur }} / v$ was set at each diffuser diffuser to ensure that the inletjet effective Reynolds number, $R_{\text {eff }}=V_{\text {in }} L_{s} /\left(v+v_{\text {tur }}\right)$, are within the range from 200 to 300 . Here $V_{\text {in }}$ is the inlet velocity value, and $L_{s}$ is the inlet length scale (the diffuser width).

The governing equations for conservation of mass, momentum, and turbulence characteristics were solved using the steady-state segregated pressure-based solver. The SIMPLEC pressure-velocity coupling scheme was used. The second-order upwind spatial discretization scheme was used for the momentum and the k- $\varepsilon$ model governing equations. The second-order pressure interpolation scheme was employed. The least square cell-based option was set as the method of computing the gradients. The Fluent solver uses under-relaxation of equations to control the update of computed variables which reduces the change of produced variable during each iteration. For the present simulation the underrelaxation factor of 0.3 was set for the pressure, the under-relaxation factors of 0.8 were set for turbulence characteristics; for the momentum the under-relaxation factor was equal to 0.7 . 


\section{Results and discussion}

\subsection{Effect of obstacles on cabin airflow}

Figure 3 shows the velocity pathlines colored with the velocity magnitude. It is visible that when the diffusers are not blocked, the jets freely spread into the cabin, the only exclusion is the jet from the forward half of the starboard diffuser №6 that interacts with the aft side wall (Figure 3a). It is not the case if CTBs are placed in the cabin aisle way near the diffusers. A comparison of the airflow pathline patterns computed for Case 1 and Case 2 demonstrate that in case of CTB allocation in the cabin, the jets from the neighboring diffusers are interrupted, and the local effect of the CTB installed influences the airflow in the surroundings. The same jet interruption is detected in Cases 3 and 4 for the diffusers that are blocked with the CTBs: the prescribed flow rate is supplied to the cabin, but the momentum of the jets is reduced significantly.

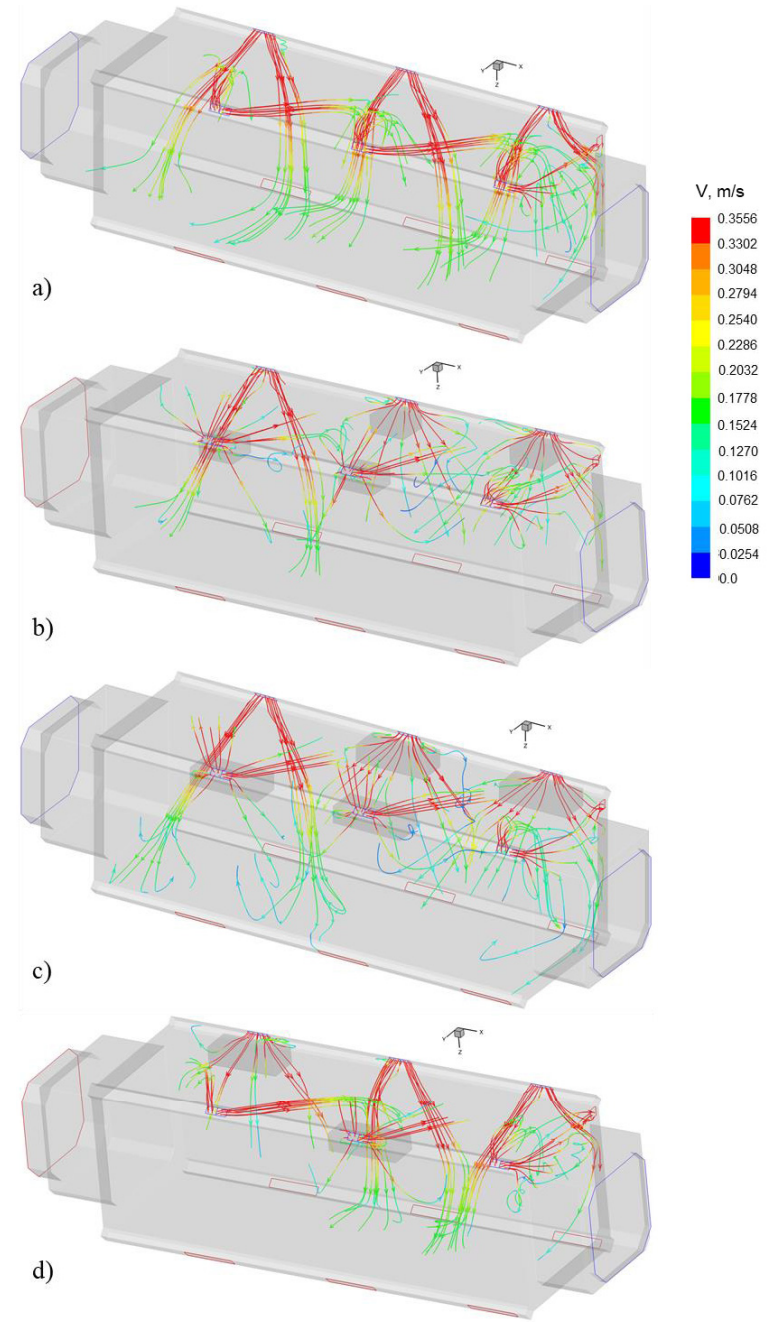

Fig. 3. Velocity pathlines issued from the U.S. Laboratory common diffusers: (a) Case 1, no CTBs; (b) Case 2, four single CTBs; (c) Case 3, four paired CTBs; (d) Case 4, two paired CTBs.

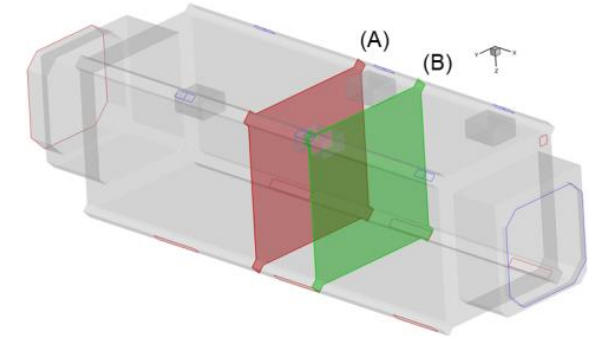

Fig. 4. Cross-sections A (red) and B (green) used for velocity postprocessing.

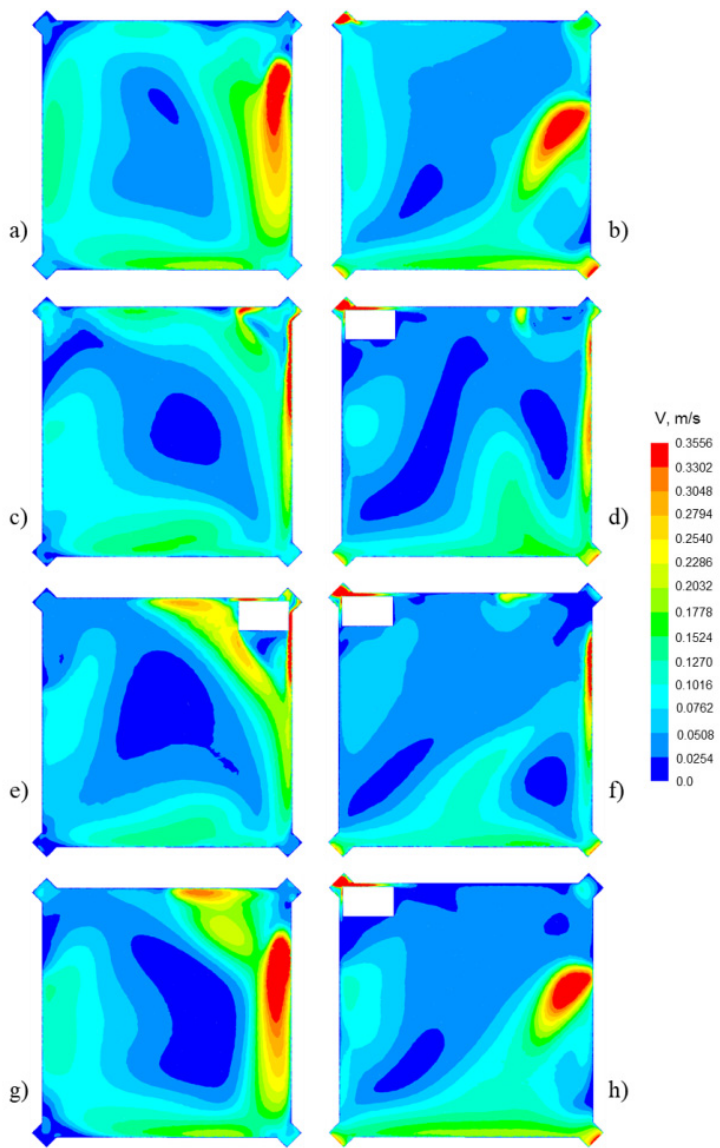

Fig. 5. Velocity magnitude distributions at vertical slices A (left) and B (right): (a, b) Case 1, no CTBs; (c, d) Case 2, four single CTBs; (e, f) Case 3, four paired CTBs; (g, h) Case 4, two paired CTBs.

Figure 5 shows velocity magnitude scalar plots at two vertical plane sections crossing the U.S. Laboratory aisle way. A comparison of velocity magnitude distributions for all four cases computed is given in the plot. The cross sections positions are illustrated in Figure 4: section (B) crosses the starboard common diffuser №5, while section (A) is placed in between the diffusers. The flow patterns presented in the figure are in accordance with the pathline plots presented in Figure 3. Localized red zones with velocities exceeding $70 \mathrm{ft} / \mathrm{min}$ $(0.3556 \mathrm{~m} / \mathrm{s})$ visible in the plots correspond to the jets issued from the diffusers and spreading under the ceiling and along the side wall. The regular ventilation is visible in the top row of plots (Figure $5 \mathrm{a}, \mathrm{b}$ ): the jets from the port diffuser №2 that freely spreads into the cabin along 
the port wall are visible in the right part of the plots. These jets are destroyed by the CTB that is visible in Figure $5 \mathrm{c}, \mathrm{d}$ : instead of large red patterns, small highvelocity zones are located in the vicinity of the port wall only. Velocity distributions in Case 3 are almost the same: paired CTBs influence the airflow similarly. As in Case 4 diffuser №2 is not blocked, the jets from the diffuser spread the same way as in Case 1: positions of the high-velocity zones in Figure $5 \mathrm{~g}$, h are almost the same as in Figure 5 a,b.

\subsection{Cabin air velocity distribution}

In order to meet the ISS ventilation requirements, most of the habitable cabin volume must be ventilated with the velocity values in the range from 15 to $40 \mathrm{ft} / \mathrm{min}$ (i.e. between 0.076 and $0.203 \mathrm{~m} / \mathrm{s}$ ), and no more than $5 \%$ of the cabin volume is with the velocities less than 15 $\mathrm{ft} / \mathrm{min}(0.076 \mathrm{~m} / \mathrm{s})$. Maintaining proper ventilation within the internal atmosphere is necessary to ensure that stagnant pockets do not form, to prevent exhaled carbon dioxide air collection around the crew head. To examine quantitatively the degree of the ISS cabin velocity requirements satisfaction, the entire cabin air velocity magnitude range is separated into five subranges (namely, below $7 \mathrm{ft} / \mathrm{min}, 7-15 \mathrm{ft} / \mathrm{min}, 15-40 \mathrm{ft} / \mathrm{min}$, $40-200 \mathrm{ft} / \mathrm{min}$, and above $200 \mathrm{ft} / \mathrm{min}$ ). Based on examination of air velocity value at each mesh cell, the sub-volumes of air with velocities from each subrange are computed for the cabin interior six inches $(0.15 \mathrm{~m})$ away from the solid walls respectively. Note that the air ventilation requirements fulfillment analysis must be performed on the basis of the time-averaged absolute velocity magnitude data.

As discussed in [11], CFD solutions based on the RANS approach produce a distribution of the absolute magnitude of the local mean velocity, or simply "velocity", abs $\left.\left.<V>=\left(<V_{\mathrm{x}}\right\rangle^{2}+<V_{\mathrm{y}}\right\rangle^{2}+<V_{\mathrm{z}}>^{2}\right)^{0.5} \equiv V_{\mathrm{m}},<>$ denotes time averaging. However, to assess thermal comfort and draught risk indexes, the mean speed values, $<$ abs $V>=<\left(V_{\mathrm{x}}^{2}+V_{\mathrm{y}}^{2}+V_{\mathrm{z}}^{2}\right)^{0.5}>\equiv V_{\mathrm{a}}$, are required. To use the RANS data in the ventilation system design, it is necessary to perform a proper conversion of the $V_{\mathrm{m}}$ data into the $V_{\mathrm{a}}$ fields. Empirical correlations derived from ultrasonic anemometer measurements were suggested for mean speed evaluation in [14]. Correlations for RANS velocity processing based on the Laser-Doppler anemometry (LDA) measurements were proposed later in [15]. Contrary to RANS, Large Eddy Simulation (LES) computations give both the velocity and the speed data directly, and it is possible to use the LES data for $V_{\mathrm{m}}$ data processing procedure development and testing. It has been done already in $[10,11]$ where a theoreticallydeveloped procedure of $V_{\mathrm{m}}$ processing has been examined using both the LES and the cabin ventilation qualification test data for the ISS pressurized module Columbus. The accuracy of the velocity-to-speed conversion procedures developed for the RANS data processing was evaluated in $[16,17]$ where LES data on mixing ventilation in a test isothermal room with a sidewall jet were compared with the experimental data
[18], namely, the LDA measurement data in the highvelocity jet zone and omnidirectional low velocity thermal anemometer data in the occupied zone.

The problem of the RANS-computed distribution of $V_{\mathrm{m}}$ transformation to the $V_{\mathrm{a}}$-field is approximately solved as the turbulence model used is based on the transport equation for the turbulent kinetic energy, $k$. Taking into account the contribution of intensive large-scale fluctuations, the mean speed, $V_{\mathrm{a}}$, can be evaluated as

$$
V_{\mathrm{a}}=\left(V_{\mathrm{m}}^{2}+5 / 3<k>\right)^{0.5},
$$

where $V_{\mathrm{m}}$ is the velocity given by a RANS solution, and $k$ is the RANS-computed turbulent kinetic energy [10]. The $V_{\mathrm{a}}$-distributions computed are shifted towards the higher velocity magnitude bands as compared with the $V_{\mathrm{m}}$-data. The flow fields computed for four cases considered were processed according to formula (1), and the results are summarized in Table 2 (velocity range limits are given in $\mathrm{m} / \mathrm{s}$ ).

It can be concluded that for the baseline case with the free aisle way of the U.S. Laboratory cabin about $50 \%$ of the volume is ventilated with the velocity values between 0.076 and $0.203 \mathrm{~m} / \mathrm{s}$. More $36 \%$ of air are with the lower velocities, from the range between 0.036 and $0.076 \mathrm{~m} / \mathrm{s}$, and about $8 \%$ of air are with the velocities below 0.036 $\mathrm{m} / \mathrm{s}$. If four single CTBs are placed in the cabin near the diffusers and block four diffusers at the same time, a pronounced shift to lower velocities is detected. In Case 2 about $55 \%$ of the cabin air is with the velocities from the range between 0.036 and $0.076 \mathrm{~m} / \mathrm{s}$, and about $20 \%$ of air is even with the lower velocities, below 0.036 $\mathrm{m} / \mathrm{s}$. Almost the same air velocity distribution is detected if the obstacles are two time larger: for Case 3 with paired CTBs that block the same four diffusers, about $57 \%$ of the cabin air is with the velocities from the range between 0.036 and $0.076 \mathrm{~m} / \mathrm{s}$, and about $19 \%$ of air is with the velocities below $0.036 \mathrm{~m} / \mathrm{s}$. If two diffusers are blocked only, the ventilation conditions are better, as about $54 \%$ of the cabin air is with the velocities from the range between 0.036 and $0.076 \mathrm{~m} / \mathrm{s}$, and less than $10 \%$ of air is within the lowest velocity range, below 0.036 $\mathrm{m} / \mathrm{s}$. However, velocity distribution still demonstrates strong shift to lower velocity range as compared with the base case.

Table 2. Distributions of absolute velocity magnitude.

\begin{tabular}{|c|c|c|c|c|}
\hline $\mathrm{V}, \mathrm{m} / \mathrm{s}$ & Case 1 & Case 2 & Case 3 & Case 4 \\
\hline $\begin{array}{c}\text { Below } \\
0.036\end{array}$ & $8.4 \%$ & $20.5 \%$ & $19.3 \%$ & $9.7 \%$ \\
\hline $\begin{array}{c}0.036- \\
0.076\end{array}$ & $36.2 \%$ & $54.9 \%$ & $56.7 \%$ & $54.3 \%$ \\
\hline $\begin{array}{c}0.076- \\
0.203\end{array}$ & $49.7 \%$ & $23.0 \%$ & $22.1 \%$ & $32.4 \%$ \\
\hline $\begin{array}{c}0.203- \\
1.016\end{array}$ & $5.7 \%$ & $1.6 \%$ & $1.9 \%$ & $3.6 \%$ \\
\hline $\begin{array}{c}\text { Above } \\
1.016\end{array}$ & $0.0 \%$ & $0.0 \%$ & $0.0 \%$ & $0.0 \%$ \\
\hline
\end{tabular}




\section{Conclusions}

The paper presents the results of the parametric CFD analyses performed for the U.S. Laboratory module with the Cargo Transfer Bags placed near the operating diffusers at various locations. Ventilation characteristics for the module were numerically predicted using the CFD software ANSYS Fluent 18. Localized effects of blocking the module interior on possible stagnant zones formation are examined and discussed.

A comparison of the airflow patterns in the U.S. Laboratory cabin aisle way resulted in conclusion that partial blockage of the diffuser with obstacles of the CTB size disrupts the ventilation air jets issued from the diffuser. There was noticeable reduction of the air jets due to interaction with the CTBs, and the module airflow patterns are sensitive to the CTB allocation. If two common diffusers are blocked at the same time, the volume that is ventilated with the velocity values from the range between 0.076 and $0.203 \mathrm{~m} / \mathrm{s}$ is reduced by one third as compared with the baseline case of free module aisle way. If four common diffusers are blocked at the same time, the volume that is ventilated with the velocity values from the range between 0.076 and $0.203 \mathrm{~m} / \mathrm{s}$ is less than one quarter of the entire module.

\section{References}

1. K.S. Prokhorov. "Life Support Systems Safety," in Safety Design for Space Systems, edited by G.E. Musgrave, A.M. Larsen and T. Sgobba, pp. 185-224 (2009).

2. H.B. Awbi, A.A. Setrak. "Air jet interference due to ceiling-mounted obstacles," in Proc. of the RoomVent 87 Conf., pp. 1-14. (1987)

3. P.V. Nielsen, L. Evensen, P. Grabau, J.H. ThulesenDahl. "Air distribution in rooms with ceilingmounted obstacles and three-dimensional isothermal flow", Aalborg University. Indoor Environmental Technology, No.3, Vol. R8714, pp. 1-11. (1987)

4. Y. Zhou, Y. Wang, K. Zheng, X. Meng. "Study on the characteristics of flow field affected by obstacle with push-pull ventilation," in Proc. of the 8th Int. Simp. on Heating, Ventilation and Air Conditioning, pp. 167-174. (2014)

5. C.H. Son, B.R. Dunaway, N.G. Ivanov, E.M. Smirnov, D.S. Telnov, SAE Int. J. of Aerospace 4, 1, pp. 525-530 (2011)

6. C.H. Son, N.G. Ivanov, E.M. Smirnov, D.S. Telnov. "CFD analysis of Node 1 ventilation and carbon dioxide transport for the maximum stowage configuration," in Proc. of the 40th Int. Conf. on Environmental Systems, AIAA 2010-6207, pp. 1-9. (2010)

7. J. Parodi, M. Hardcastle, M. Flynn, S.Gormly, L. Grizzaffi, C. Lobascio, L. Gemelli. "Progress and direction of the forward osmosis-cargo transfer bag concept for 2013," in Proc. of the 44th Int. Conf. on Environmental Systems, pp. 1-13. (2014)
8. C.H. Son, N.G. Ivanov, E.M. Smirnov, D.S. Telnov. "CFD-Based evaluation of inlet diffuser cluttering effects on the international space station cabin atmosphere," in Proc. of the 48th Int. Conf. on Environmental Systems, pp. 1-8. (2018)

9. C.H. Son, N.G. Ivanov, E.M. Smirnov, D.S. Telnov. "CFD Analysis for Oxygen Concentration during Respiratory Support Pack Operation," in Proc. of the 40th Int. Conf. on Environmental Systems, AIAA 2010-6208, pp. 1-8. (2010)

10. E.M. Smirnov, N.G. Ivanov, D.S. Telnov, C.H. Son, V.K. Aksamentov. "Computational Fluid Dynamics study of air flow characteristics in the Columbus module," in Proc. of the 34th Int. Conf. on Environmental Systems, SAE Technical Paper 200401-2500, pp. 1-8. (2004)

11. E.M. Smirnov, N.G. Ivanov, D.S. Telnov, C.H. Son, Int. J. of Ventilation 5, 2, pp. 219-228 (2006)

12. T.-H. Shih, W.W. Liou, A. Shabbir, Z. Yang, J. Zhu, Computers and Fluids 24, 3, p. 227-238 (1995)

13. B.E. Launder, D.B. Spalding, Computer Methods in Applied Mechanics and Engineering 3, pp. 269-289 (1974)

14. H. Koskela, J. Heikkinen, R. Niemela, T. Hautalampi, Building and Environment 36, 2, pp. 247-255 (2001)

15. Z. Popiolek, A. Melikov. "Improvement of CFD predictions of air speed turbulence intensity and draught discomfort," In Proc. of 11 Int. Conf. on Indoor Air Quality and Climate, pp. 1-8 (2008)

16. M.A. Zasimova, N.G. Ivanov. "Numerical simulation of air distribution in a room with a sidewall jet under benchmark test conditions," AIP Conference Proceedings 1959, 050033, pp. 1-8 (2018)

17. N.G. Ivanov, M.A. Zasimova. "Large Eddy Simulation of airflow in a room with a sidewall jet: comparison with benchmark test data for occupied zone," in Proc. of Roomvent \& Ventilation 2018: Excellent Indoor Climate and High Performing Ventilation pp. 319-324 (2018)

18. M. Hurnik, M. Blaszczok, Z. Popiolek, Building and Environment 93, pp. 319-330 (2015) 